\title{
Preoperative multidetector-row computed tomography scan staging for lymphatic gastric cancer spread
}

\author{
Paolo Morgagni ${ }^{*}$, Enrico Petrella², Barbara Basile², Alberto Mamii ${ }^{2}$ Augusto Soro ${ }^{2}$, Andrea Gardini ${ }^{1}$, \\ Filippo Calzolari', Domenico Garcea ${ }^{1}$ and Mauro Bertocco ${ }^{2}$
}

\begin{abstract}
Background: Multidetector-row computed tomography (MDCT) is commonly used to stage patients with gastric cancer, even though the technique often shows low specificity for lymph-node involvement.

Methods: In this study, 111 patients with gastric cancer who consecutively underwent MDCT scan followed by radical surgical treatment at our hospital were retrospectively evaluated.

Results: In total, 3632 lymph nodes from 643 lymphatic stations were studied and then correlated with radiological features. Lymph-node size was not always associated with infiltration. Of the 261 lymph-node stations that were not radiologically detected, 60 (22.9\%) were infiltrated. There were 108 stations with lymph nodes larger than $10 \mathrm{~mm}$ seen on MDCT, of which 67 (62\%) had lymphatic invasion. The sensitivity was $32.6 \%$, specificity $90.6 \%$, positive predictive value $62.0 \%$, negative predictive value $74.2 \%$, and accuracy $72.1 \%$. When three lymph nodes, at least one of which was larger than $10 \mathrm{~mm}$, were detected in the same station, infiltration was confirmed with $99 \%$ specificity in $93.8 \%$ of patients. Moreover, all of the 13 patients in whom three lymph nodes larger than $10 \mathrm{~mm}$ were detected in different neighboring stations had lymphatic invasion.
\end{abstract}

Conclusions: Although presence of lymph nodes greater than $10 \mathrm{~mm}$ in size is not, in itself, sufficient to confirm lymphatic invasion, nodal involvement can be hypothesized when associated images are detected by MDCT.

Keywords: MDCT staging, Gastric cancer, Lymph-node diffusion, Preoperative setting

\section{Background}

With the exception of early lesions, gastric cancer is generally considered a tumor with a poor prognosis, and surgical treatment alone does not offer great hope to patients with serosal involvement or lymphatic diffusion. Given that neoadjuvant treatments are currently proposed for advanced cancer, the preoperative stage of the tumor must be determined first in order to avoid using inappropriate medical treatment in patients who are potentially radically treatable by endoscopic or surgical therapy. Although improvements in endoscopic ultrasonography are continuously being made in terms of defining cancer infiltration, the accuracy of this method in

\footnotetext{
* Correspondence: p.morgagni@ausl.fo.it

'Department of General Surgery, Morgagni-Pierantoni Hospital, Via Forlanini 34, Forli, Italy

Full list of author information is available at the end of the article
}

identifying suspect non-perigastric lymph-node involvement and metastases remains poor.

One of the most widely used diagnostic methods for staging of these patients is multidetector-row computed tomography (MDCT) [1-3], which has high sensitivity in identifying distant metastases or enlarged lymph nodes, but is often inadequate in recognizing lymph-node metastasis. Although lymph nodes larger than $10 \mathrm{~mm}$ in size are generally considered to be positive, other criteria for identifying involved nodes have been reported in the literature, including a size of greater than $6 \mathrm{~mm}$ plus round shape; size of greater than $8 \mathrm{~mm}$ on the short axis, size of greater than $8 \mathrm{~mm}$ irrespective of axis; or simply radiologically detection of the node [1]. The concept of bulky lymph nodes has emerged from literature data to define a high suspicion of malignant lymph-node infiltration when lymph nodes are greater than $30 \mathrm{~mm}$
C Biomed Central

(c) 2012 Morgagni et al.; licensee BioMed Central Ltd. This is an Open Access article distributed under the terms of the Creative Commons Attribution License (http://creativecommons.org/licenses/by/2.0), which permits unrestricted use, distribution, and reproduction in any medium, provided the original work is properly cited. 
in size or there are more than three lymph nodes measuring $15 \mathrm{~mm}$ each present in neighboring stations [3].

The aim of this study was to correlate lymphatic size and infiltration in our patients, and to verify whether 16-row MDCT could effectively help to identify patients with node-positive cancer for neoadjuvant treatment.

\section{Methods}

Ethics approval

As MDCT scan and lymphatic dissection were considered the standard treatment for all our patients, ethics approval was not needed and only informed written consent was obtained.

\section{Patients and treatment}

From January 2009 to January 2011, we analyzed 111 patients with gastric cancer at Morgagni-Pierantoni Hospital in Forlì, who had consecutively undergone 16row MDCT scan followed by radically treatment. During this period, a standard approach for MDCT scan was used by the radiology unit of our hospital for cases of suspected gastric cancer. Specifically, after a 12-hour fast, patients were required to drink $600 \mathrm{ml}$ of water and then lie down in a supine position (for gastric cancer of the antrum-corpus) or a prone position (for gastric cancer of the upper third of the tract). Patients were give $20 \mathrm{mg}$ of scopolamine N-butyl bromide (Buscopan ${ }^{\circledR}$; Boehringer Ingelheim, Tokyo, Japan) as an intravenous bolus infusion. The technical parameters required are described in Table 1.

The results from all MDCT scans were revised for this study by five radiologists in order to accurately determine lymph-node shape and size along the major axis in the area of the stations dissected by surgeons. Lymph-node size was arbitrarily subdivided into five categories (major axis $<5 \mathrm{~mm}, 5$ to $<10 \mathrm{~mm}, 10$ to $<15 \mathrm{~mm}, 15$ to $<20 \mathrm{~mm}$, and $\geq 20 \mathrm{~mm}$ ). All radiologically detected lymph nodes were separately registered for each lymphatic station in accordance with Japanese Gastric Cancer Association (JGCA) recommendations [4], with special attention being paid to associations of enlarged

Table 1 Technical parameters required for multidetectorrow computed tomography

\begin{tabular}{ll}
\hline Pre-contrast phase thickness & $3.75 \mathrm{~mm}$ \\
\hline Arterial phase thickness & $2.5 \mathrm{~mm}$ \\
Portal phase thickness & $2.5 \mathrm{~mm}$ \\
Pitch & 1.25 \\
Rotation time & $0.5 \mathrm{~seconds}$ \\
Contrast & $2 \mathrm{ml} / \mathrm{kg}$ at $3.5 \mathrm{ml} / \mathrm{second}$ \\
Arterial phase with smart prep, venous phase at 70 seconds \\
Reconstructions on sagittal and coronal planes
\end{tabular}

lymph nodes such as three lymph nodes in the same station or presence of enlarged lymph nodes in nearby stations. Dissected stations where only fatty tissue was identified (as frequently occurs in the suprapyloric station) were not considered for this study.

Subtotal gastrectomy was then performed for tumors sited in the lower two-thirds of the stomach, whereas total gastrectomy without standard splenectomy was carried out for tumors in the upper third of the stomach. Both interventions were completed by level I or II lymphadenectomy (D1 or D2), based on the age and condition of the patient [4], and removal of the greater and lesser omentum. All lymphatic stations were dissected by surgeons immediately after resection for separate

Table 2 Patient characteristics

\begin{tabular}{|c|c|c|}
\hline \multirow{2}{*}{$\begin{array}{l}\text { Patient } \\
\text { characteristics }\end{array}$} & \multicolumn{2}{|c|}{ Patients } \\
\hline & $\mathbf{n}$ & $\%$ \\
\hline \multicolumn{3}{|l|}{ Sex } \\
\hline Male & 57 & 51.3 \\
\hline Female & 54 & 48.7 \\
\hline \multicolumn{3}{|l|}{ Histology } \\
\hline Intestinal & 89 & 80.2 \\
\hline Diffuse mix & 22 & 19.8 \\
\hline \multicolumn{3}{|l|}{ T staging } \\
\hline T1a & 17 & 15.3 \\
\hline $\mathrm{T} 1 \mathrm{~b}$ & 14 & 12.6 \\
\hline $\mathrm{T} 2$ & 6 & 5.4 \\
\hline T3 & 23 & 20.7 \\
\hline T4a & 46 & 41.5 \\
\hline T4b & 5 & 4.5 \\
\hline \multicolumn{3}{|l|}{ N staging } \\
\hline No & 44 & 39.6 \\
\hline N1 & 15 & 13.5 \\
\hline $\mathrm{N} 2$ & 14 & 12.6 \\
\hline N3a & 16 & 14.5 \\
\hline N3b & 22 & 19.8 \\
\hline \multicolumn{3}{|l|}{ Tumor site } \\
\hline Upper third & 28 & 25.2 \\
\hline Middle third & 28 & 25.2 \\
\hline Lower third & 55 & 49.6 \\
\hline \multicolumn{3}{|l|}{ Tumor size, mm } \\
\hline$\leq 2$ & 14 & 12.6 \\
\hline$>2$ to $\leq 4$ & 38 & 34.2 \\
\hline$>4$ & 59 & 53.2 \\
\hline \multicolumn{3}{|c|}{ Lymph-node dissection } \\
\hline D1 & 9 & 8.1 \\
\hline D2 & 102 & 91.9 \\
\hline
\end{tabular}


Table 3 Correlation between radiological size and clinical characteristics

\begin{tabular}{lccc}
\hline Lymph nodes & $\begin{array}{c}\text { Total } \\
\text { stations, } \mathbf{n}\end{array}$ & $\begin{array}{c}\text { Positive } \\
\text { stations, } \mathbf{n}\end{array}$ & $\begin{array}{c}\text { Total stations/positive } \\
\text { stations, \% }\end{array}$ \\
\hline $\begin{array}{l}\text { Dissected but not } \\
\text { radiologically } \\
\text { detected }\end{array}$ & 261 & 60 & 22.9 \\
Size, $\mathrm{mm}$ & & & \\
$<5$ & 75 & 12 & 16 \\
$\geq 5$ to $<10$ & 199 & 66 & 33.1 \\
$\geq 10$ to $<15$ & 83 & 50 & 60.2 \\
$\geq 15$ to $<20$ & 22 & 14 & 63.6 \\
$\geq 20$ & 3 & 3 & 100 \\
\hline
\end{tabular}

histological examination. Tumors were classified in accordance with the Union for International Cancer Control tumor, node, metastasis (UICC TNM) classification (seventh edition) [5].

We then correlated the shape and size of radiologically detected lymph nodes in each lymphatic station with the histological diagnosis of any lymph nodes dissected in that station. To assess the correlation between the size of MDCT-detected lymph nodes and infiltration, stations were considered radiologically positive if at least one lymph node was detected by imaging in that area, and histologically involved if at least one of the separately dissected lymph nodes was infiltrated. Clinical, radiologic, and pathologic data were stored in the database. Sensitivity, specificity, positive and negative predictive value (PPV and NPV), accuracy, and likelihood of lymph-node involvement were determined to evaluate diagnostic efficiency.

\section{Results}

The characteristics of the 111 patients are summarized in Table 2. In total, 3632 lymph nodes from 643 stations were dissected (median 32.7 lymph nodes/patient). There were 832 lymph nodes detected by our radiologists in 382 stations; 75 stations had lymph nodes smaller than $5 \mathrm{~mm}$ in size, whereas 83 had lymph nodes that were $10 \mathrm{~mm}$ or larger. Only three stations with lymph nodes larger than $20 \mathrm{~mm}$ were seen in our series.

Of the 382 MDCT-detected lymph-node stations, 237 were histologically negative and 145 were infiltrated. Correlations between radiological size and pathological station involvement are summarized in Table 3. Although the percentage of involved stations rose as lymph-node size increased, low sensitivity and specificity (Table 4). In particular, only $22.9 \%$ of the 261 stations not radiologically detected were infiltrated; taking into consideration radiologically detected lymph nodes, $16 \%$ of the stations with nodes smaller than $5 \mathrm{~mm}, 33 \%$ of the stations with nodes between 5 and $10 \mathrm{~mm}$, and 63\% of stations with nodes between 15 and $20 \mathrm{~mm}$ were histologically infiltrated. Conversely, when the association of lymph nodes was analyzed, a higher percentage of positive lymph nodes was detected when there were three or more lymph nodes in the same station and one of these was larger than $10 \mathrm{~mm}$ in size (Figure 1). Stations with these characteristics were positive in $93.8 \%$ of cases and, although sensitivity was low, specificity was high. Furthermore, associations of three lymph nodes larger than $10 \mathrm{~mm}$ in neighboring stations always identified patients with lymphatic involvement (Table 5). Taking lymph-node size into consideration, the sensitivity fell and specificity rose as size increased.

PPV, which was lower in non-radiologically detected lymph nodes $(37.9 \%)$, increased to $100 \%$ when lymph nodes larger than $20 \mathrm{~mm}$ were present. NPV decreased from $77 \%$ to $68.4 \%$ and accuracy increased from 53.8 to 68.4\%. Sensitivity was very low, but specificity and PPV were high when the two associations of lymph nodes previously described were taken into consideration (Table 5). The likelihood ratio (LR) also increased as lymph-node size increased, but was very high in patients with one lymph node larger than $10 \mathrm{~mm}$ and two radiologically detected lymph nodes in the same station. The LR for these data was 32.7 (95\% CI 10.3 to 104)

Table 4 Correlation between radiological size of the largest lymph node per station and sensitivity, specificity, predictive value, accuracy, and likelihood ratio

\begin{tabular}{|c|c|c|c|c|c|c|c|c|}
\hline Lymph nodes & $\begin{array}{c}\text { Radiologically } \\
\text { detected }\end{array}$ & $\begin{array}{l}\text { Pathologically } \\
\text { infiltrated }\end{array}$ & Sensitivity & Specificity & PPV & NPV & Accuracy & LR $(95 \% \mathrm{Cl})$ \\
\hline $\begin{array}{l}\text { All radiologically detected } \\
\text { lymph nodes }\end{array}$ & 382 & 145 & 70.7 & 45.8 & 37.9 & 77 & 53.8 & $1.30(1.15$ to 1.47$)$ \\
\hline \multicolumn{9}{|l|}{ Size, mm } \\
\hline$<5$ & 307 & 133 & 64.8 & 60.2 & 43.3 & 78.5 & 61.7 & $1.63(1.40$ to 1.90$)$ \\
\hline$\geq 10$ & 108 & 67 & 32.6 & 90.6 & 62.0 & 74.2 & 72.1 & 3.49 (2.45 to 4.96$)$ \\
\hline$\geq 15$ & 25 & 17 & 6.8 & 98.1 & 63.6 & 69.2 & 69 & $3.73(1.59-8.77)$ \\
\hline$\geq 20$ & 3 & 3 & 1.4 & 100 & 100 & 68.4 & 68.5 & Not measurable \\
\hline
\end{tabular}

LR, likelihood ratio; NPV, negative predictive value; PPV, positive predictive value. 


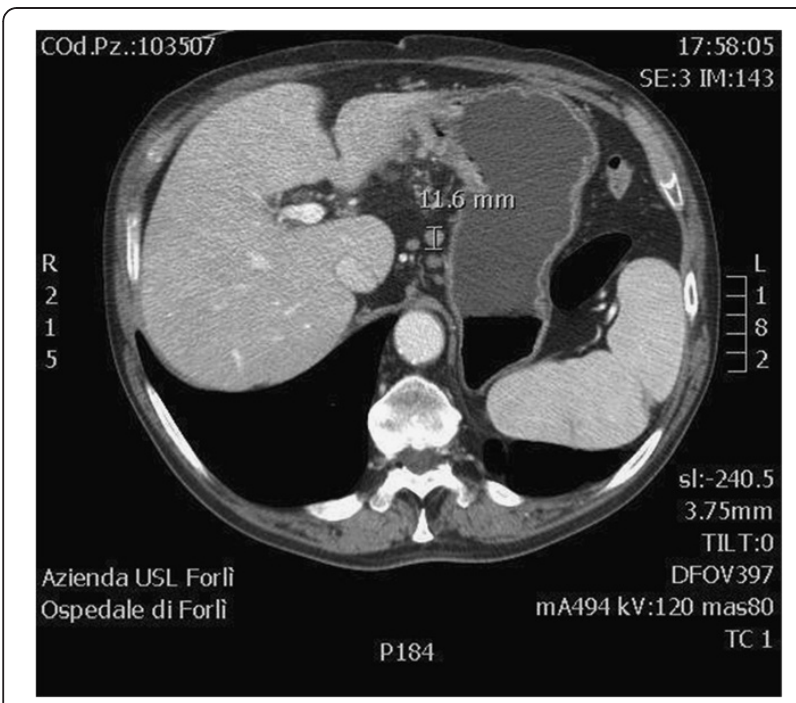

Figure 1 Three positive lymph nodes were detected in the same station, one of which was larger than $10 \mathrm{~mm}$.

With regard to lymph-node shape, $46.1 \%$ of overall lymph nodes were round and $53.9 \%$ were oval while $49.3 \%$ of positive dissected lymph nodes were round and $50.7 \%$ were oval.

\section{Discussion}

In recent years, increased interest in integrated treatments, especially in a neoadjuvant setting, has led to more accurate preoperative staging and to better selection of patients who are candidates for more specific treatment.

Although MDCT scan is not considered the gold standard technique for $\mathrm{T}$ and perigastric $\mathrm{N}$ staging (sensitivity and specificity range from $60 \%$ to $90 \%$ ) $[1,6]$, it is nevertheless the most widely used standard diagnostic tool. Conversely, echo-endoscopy, considered by several authors as the most accurate method to study tumor growth and perigastric nodes (median sensitivity and specificity values reported in the literature of $70.8 \%$ and $84.6 \%$, respectively, or $95.3 \%$ and $100 \%$ in selected centers) [1], is not always performed, and does not have a high level of accuracy in identifying distant lymph nodes. This problem is further increased by the new TNM staging system, which requires the selective identification of single lymph nodes to differentiate between N1, N2, and N3 stages. Numerous studies have been published on the correlation between lymph-node dimensions and neoplastic infiltration, and a size of $10 \mathrm{~mm}$ is generally considered to have a high degree of suspicion for infiltration [2]. Different criteria have been proposed for defining metastatic infiltration, including size of $6 \mathrm{~mm}$ along the short axis diameter of perigastric lymph nodes [7]; $8 \mathrm{~mm}$ along the short [8] or greater axis [9]; or size associated with other characteristics such as marked enhancement [2], necrosis [7], shape [8] or fat content $[7,10,11]$. Other authors consider all identifiable lymph nodes to be positive $[1,12]$.

Several studies have estimated the $\mathrm{N}$ radiological stage by taking into consideration the distance between lymph node and tumor $[7,12]$ (old TNM) or lymphatic station level, as reported by the JGCA [8], but few studies have considered single lymph-node stations [13]. In the current study, it was not possible for us to study lymph nodes separately, and we therefore evaluated single stations dissected by the surgeon at the end of the surgical treatment. Our data failed to confirm a close correlation between size and infiltration, although increased lymph node size was more frequently associated with metastasis. In particular, metastases were found in $22.9 \%$ of undetected lymph nodes and only in about $60 \%$ of lymph nodes $10 \mathrm{~mm}$ in size. Although lymph nodes larger than $20 \mathrm{~mm}$ were always infiltrated, few were identified and all showed low sensitivity. Furthermore, shape alone was not a specific criterion to define infiltration, with at least $50 \%$ of the detected lymph nodes being oval-shaped.

Yoshikawa et al. defined 'bulky lymph node metastasis' as one node of $30 \mathrm{~mm}$ or larger in diameter, or at least three consecutive nodes each $15 \mathrm{~mm}$ or larger in firstor second-level lymph-node stations [3]. Although we did not observe any lymph nodes larger than $30 \mathrm{~mm}$, and very few patients had an association of three lymph nodes of $15 \mathrm{~mm}$ or more in size, we found that the association of three lymph nodes, one of which larger than $10 \mathrm{~mm}$, was generally associated with infiltration, with

Table 5 Size of lymph nodes and station involvement when associated lymph nodes were reported; sensitivity, specificity, predictive value, accuracy and likelihood ratio

\begin{tabular}{|c|c|c|c|c|c|c|c|c|}
\hline Characteristic & $\begin{array}{c}\text { Radiologically } \\
\text { detected }\end{array}$ & $\begin{array}{l}\text { Pathologically } \\
\text { infiltrated }\end{array}$ & Sensitivity & Specificity & PPV & NPV & Accuracy & LR $(95 \% \mathrm{Cl})$ \\
\hline $\begin{array}{l}\text { Stations with } \geq 3 \text { lymph nodes } \\
\text { radiologically detected, one of } \\
\text { which was }>10 \mathrm{~mm}\end{array}$ & 49 & 46 & 22.4 & 99.3 & 93.8 & 88.0 & 74.8 & $\begin{array}{c}32.7(10.31 \text { to } \\
104.0)\end{array}$ \\
\hline $\begin{array}{l}\text { Patients with }>3 \text { lymph nodes } \\
>10 \mathrm{~mm} \text { in neighboring } \\
\text { stations }\end{array}$ & 13 & 13 & 6.3 & 100 & 100 & 69.5 & 70.1 & Not measurable \\
\hline
\end{tabular}


49 stations having this characteristic, and infiltration being detected in 46 of these. Only one of the two patients who did not show any correlation was staged N0, whereas the other was staged N3. The presence of lymph nodes larger than $10 \mathrm{~mm}$ in neighboring stations was seen in 13 patients, all of whom had lymphatic involvement, even though some large lymph nodes analyzed were histologically negative (Table 5 ). Even though sensitivity was low and few patients were involved, we believe that these two lymph-node correlations could be important criteria to select individuals with lymphatic spread because of the high specificity (almost 100\%).

\section{Conclusions}

MDCT scans are widely used in preoperative gastric cancer staging. In this study, perigastric lymph-node dimensions showed low sensitivity and higher specificity as node size increased, and evaluation of larger lymph nodes located in the same area led to increased accuracy. Because sensitivity, specificity, and accuracy of lymphnode dimensions alone would not seem to predict lymph-node infiltration, further research is needed to find correlations between node size and other characteristics in order to guarantee adequate preoperative staging. Although we only analyzed a small number of patients, the correlation found between the number of lymph nodes and their size is interesting and, if supported by larger, statistically analyzed studies, could help to identify patients who are candidates for preoperative treatment.

\section{Competing interests}

The authors declare that they have no competing interests.

\section{Authors' contributions}

$P M, B B, E P$, and $D G$ were involved in study conception and design; EP, AM, $F C, B B, P M$, and $A S$ carried out data acquisition; $E P, A M, F C, B B, P M$, and $A G$ were responsible for quality control of data and algorithms; AG and PM carried out data analysis and interpretation; PM, DG and FC drafted the manuscript. All authors read and approved the final manuscript.

\section{Author details}

'Department of General Surgery, Morgagni-Pierantoni Hospital, Via Forlanini 34, Forli, Italy. ${ }^{2}$ Radiology Unit, Morgagni-Pierantoni Hospital, Via Forlanini 34, Forlì, Italy.

Received: 7 June 2012 Accepted: 13 September 2012

Published: 24 September 2012

\section{References}

1. Kwee RM, Kwee TC: Imaging in assessing lymph node status in gastric cancer. Gastric Cancer 2009, 12:6-22.

2. Park SR, Kim MJ, Ryu KW, Lee JH, Lee JS, Nam BH, Choi IJ, Kim YW: Prognostic value of preoperative clinical staging assessed by computed tomography in resectable gastric cancer patients. Ann Surg 2010, 251:428-435.

3. Yoshikawa T, Sasako M, Yamamoto S, Sano T, Imamura H, Fujitani K, Oshita H, Ito S, Kawashima Y, Fukushima N: Phase II study of neoadjuvant chemotherapy and extended surgery for locally advanced gastric cancer. Br J Surg 2009, 96:1015-1022.

4. Japanese Gastric Cancer Association: Japanese Classification of Gastric Carcinoma, second English edition. Gastric Cancer 1998, 1:10-24.
5. Sobin LH, Wittekind C: TNM classification of malignant tumors. 7th edition. New York, NY: Wiley; 2009.

6. Hwang SW, Lee DH, Lee SH, Park YS, Hwang JH, Kim JW, Jung SH, Kim NY, Kim YH, Lee KH, Kim HH, do Park J, Lee HS, Jung HC, Song IS: Preoperative staging of gastric cancer by endoscopic ulotrasonography and multidetector-row computed tomography. J Gastroenterol Hepatol 2010, 25:512-518

7. Yan C, Zhu GZ, Yan M, Zhang H, Pan ZL, Chen J, Xiang M, Chen MM, Liu BY, Yin HR, Lin YZ: Value of multidetector-row computed tomography in preoperative $\mathrm{T}$ and $\mathrm{N}$ staging of gastric carcinoma: a large scale Chinese study. J Surg Oncol 2009, 100:205-214.

8. Kim HJ, Kim A, ST O, Kim JS, Kim KW, Kim PN, Lee MG, HK H: Gastric cancer staging at multi-detector row ct gastrography: comparison of transverse and volumetric CT scanning. Radiology 2005, 236:879-885.

9. Chen CY, Hsu JS, Wu DC, Kang WY, Hsieh JS, Jaw TS, Wu MT, Liu GC: Gastric cancer: preoperative local staging with 3-D multidetector row CT. Correlation with surgical and histopathologic results. Radiology 2007, 242:472-482.

10. Kim YN, Choi D, Kim SH, Kim MJ, Lee SJ, Lee WJ, Kim S, Kim JJ: Gastric cancer staging at isotropic MDCT including coronal and sagittal MPR images: endoscopically diagnosed early versus advanced cancer. Abdom Imaging 2009, 34:26-34.

11. Chen BB, Liang PC, Liu KL, Hsiao JK, Huang JC, Wong JM, Lee PH, Shun CT, Ming-Tsang Y: Preoperative diagnosis of gastric tumors by three dimensional multidetector row CT and double contrast barium meal study; correlation with surgical and histologic results. J Formos Med Assoc 2007, 106:943-952.

12. Yang DM, Kim HC, Jin W, Ryu CW, Ryu CW, Kang JH, Park CH, Kim HS, Jung DH: 64 multidetector-row computed tomography for preoperative evaluation of gastric cancer: histological evaluation. J Comput Assist Tomogr 2007, 31:98-103.

13. Marrelli D, Mazzei MA, Pedrazzani C, Di Martino M, Vindigni C, Corso G, Morelli E, Volterrani L, Roviello F: High accuracy of multislice computed tomography (MSCT) for paraortic lymph node metastases for gastric cancer: a prospective single center study. Ann Surg Oncol 2011, 18:2265-2272.

doi:10.1186/1477-7819-10-197

Cite this article as: Morgagni et al:: Preoperative multidetector-row computed tomography scan staging for lymphatic gastric cancer spread. World Journal of Surgical Oncology 2012 10:197.

\section{Submit your next manuscript to BioMed Central and take full advantage of:}

- Convenient online submission

- Thorough peer review

- No space constraints or color figure charges

- Immediate publication on acceptance

- Inclusion in PubMed, CAS, Scopus and Google Scholar

- Research which is freely available for redistribution 